\section{Texting the Doctor}

A recent Boston Globe article profiled the rise in concierge medical practices: primary care providers who forsake traditional fee-for-service or insurance coverage in exchange for a flat fee for annual services. The cost is usually between $\$ 1500$ and $\$ 2000$ per year, paid directly by the patient. It makes sense that, having plunked down a couple grand for services, patients feel entitled to certain levels of care. What is apparently the first thing they ask for: A comprehensive 60-minute review on healthy diets or the virtues of exercise? No. A detailed cardiovascular exam, with careful palpation of each peripheral pulse, and elaborate auscultation of the heart using the stethoscope in 18 different ways, as taught in DeGowin $\mathcal{E}$ DeGowin? No. It is, of course, the doctor's cell phone number.

As much as expertise, patients want access. This is not a new phenomenon. A classic pearl from a previous generation held that doctors need 3 kinds of ability, in descending order: availability, affability, and ability. The rise of the internet-and evolving changes in interpersonal communication with cell phones, e-mail, and texting - has accelerated and intensified the apparent need for speedy contact.

Cancer patients have as much need for speedy information as anyone, and maybe more. David Rakoff, writing in The New York Times Sunday Magazine (http://www. nytimes.com/2011/04/17/magazine/mag-17lives-t.html?ref=magazine), described his experiences as a sarcoma patient. He entitled his essay "The Waiting" and described waiting for biopsy results, waiting for CT scan results, waiting for the doctor, waiting for an update on his cancer status. Having spent years in treatment, and knowing his medical team all too well, Rakoff prefers a cut-to-the-chase approach. "The doctors and nurses in my life don't prolong the anticipation with pleasantries. We joke around a lot, but that's the second order of business. With a long illness, there are stretches of triumph that feel like cosmic rewards for good behavior followed by inexplicable setbacks that seem like indictments of your character. With so much muddy logic crowding out reason, it's best when news, good or bad, is delivered quickly and clearly."

For those of us who are so old-fashioned that we make ourselves available to patientswith appointments, office phone numbers, beepers, cell phones, and e-mail, and without extra charge, no less-the urge for expediency is a double-edged sword. There is the undeniable efficiency of the quick reply that settles a question, refers a matter, or clarifies a problem in moments, and that would otherwise take far longer and be more disruptive. This works well for much that arises in management, and works particularly well for patients with whom the medical team has a long-standing relationship and a clear sense of expectations and trust and when the matter can be briskly settled.

That does not describe every patient-doctor relationship, however, or every medical moment. Rakoff prefers that news is delivered quickly, and also clearly. This latter point is where rapid-fire 21st century media solutions may not be so useful. Not every oncology question can be settled in a 142-character text message, or even a page-long e-mail. The temptation for both doctors and patients to reach quick resolution with a snappy instant text reply may not always be appropriate. The key requirement is clarity; clarity in the explanation and clarity in the plan.

The pressure for rapid communication of all medical information will only grow. As patients get real-time access to their electronic medical records and our ability to relay text and video at breathtaking speed all over the globe accelerates, the expectation will be for more and more instant feedback and comment. This poses logistical problems, because these kinds of communications are beyond the reach current structures in both medical records and medical billing. But the real challenge for health care providers will be to figure out when digital contact is the solution and when it is not. Someone needs to write an app for that.

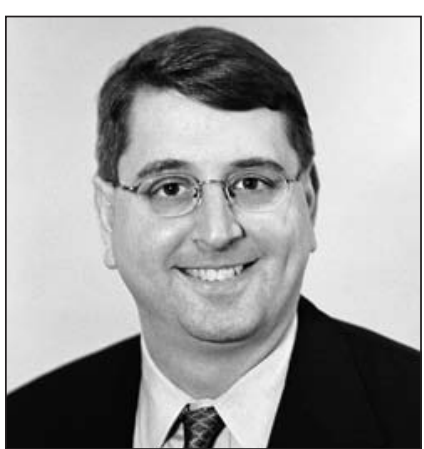

Harold J. Burstein, MD, PhD

Harold J. Burstein, MD, PhD, editor-in-chief of JNCCN, is an Associate Professor of Medicine at Harvard Medical School and a medical oncologist at Dana-Farber Cancer Institute and Brigham \& Women's Hospital. He is a clinician and clinical investigator specializing in breast cancer.

Dr. Burstein attended Harvard College and earned his MD at Harvard Medical School, where he also earned a PhD in immunology. He trained in internal medicine at Massachusetts General Hospital and was a fellow in medical oncology at Dana-Farber before joining the staff.

Dr. Burstein's clinical research interests include novel treatments for early- and advanced-stage breast cancer and studies of quality of life and health behavior among women with breast cancer. He has written widely on breast cancer in both traditional medical journals and on the web, including New England Journal of Medicine and Journal of Clinical Oncology. International committees focusing on cancer treatments that he has or continues to participate in include the NCCN Clinical Practice Guidelines Breast Cancer Panel, St. Gallen Breast Cancer Panel, CALGB Breast Cancer Committee, ASCO Health Services Research and Clinical Research Committees, the National Quality Forum Breast Cancer Technical Panel, and other ASCO expert panels.

The ideas and viewpoints expressed in this editorial are those of the author and do not necessarily represent any policy, position, or program of the NCCN. 